\title{
Effect of Self-Instructional Module on Skills of Caregivers of Children with Cerebral Palsy
}

\author{
Iman Badran \\ PhD Nursing, BVDU College of Nursing, Pune, India
}

\begin{abstract}
Because Cerebral Palsy is a handicapping condition with known CNS aetiology, it is essential to assess, monitor, and provide interventions to promote development and acquisition of skills, thus optimizing potential.Purpose: To study the effect of selfinstructional module on skills of caregivers of children with Cerebral Palsy. Objectives: To assess the effect of self-instructional module on skills of caregivers of children with Cerebral Palsy. Material and methods: This was a quantitative descriptive survey pilot study with pre-test and post-test research design. The sample size was 10 caregivers of children with Cerebral Palsy and consists of one group of caregivers. Purposive sampling technique was used for the selection of sample. The group was having 10 samples and received information booklet as an intervention in Bharati Hospital, Pune during February 2015 to Jun 2015. Tool was developed in two parts, first was demographic data of the caregivers, second self reported practice questionnaire. Skills of caregivers before and after administration of Information Booklet were assessed in five aspects: carrying and positioning, communication, feeding, activities of daily living, and use of assistive devices. Results: Majority of children with Cerebral Palsy were males while female with Cerebral Palsy included a small population and none of these children had other siblings affected by Cerebral Palsy. The mean skills score from $52.8 \%$ in the pre-test to $68 \%$ in the post-test. Skills of caregivers before and after administration of Information Booklet were assessed in 5 aspects carrying and positioning, communication, feeding, activities of daily living, and use of assistive devices. Distributions of subjects during post-test were higher as compared during pre-test in each aspect.Conclusion: They study concluded that there was a significant increase in the skills of caregivers of children with Cerebral Palsy.
\end{abstract}

Keywords: Self-instructional Module, Caregiver, Cerebral Palsy

\section{Introduction}

Aside from knowledge of the condition, the primary focus for management of the child with Cerebral Palsy is to promote optimal function; to foster acquisition of new skills; to maintain general health; to assist and educate parents and caregivers, and to participate, and prevent, and treat the complications of the disorders. (Jones, Morgan \& Shelton, 2007) ${ }^{1}$

The prognosis for children with Cerebral Palsy is extremely crucial. Best clinical outcomes results of Cerebral Palsy management will happen with early involvement of interdisciplinary team effort of management of the child with Cerebral Palsy, which include the occupational, physical speech therapist, educational, and vocational therapist primary care physician, psychologist, and vocational therapist. (Zolotor \& Kane, 2012) ${ }^{2}$

\section{Review of Literature}

Coordinated services for early detection are necessary to assist families in gaining access to services that support healthy development of children at a high risk of having developmental delays. (Cunningham, et al., 2004) However, early intervention services starts when the child shows significant developmental skills delay or when risk factors associated with motor disorders are identified. The initiation of services often precedes a definitive diagnosis of Cerebral Palsy. ${ }^{4}$

There is paucity of evidence-based intervention aimed to evaluate the impact of that intervention on the parental knowledge regarding Cerebral Palsy. (Khana Arora, 2014) ${ }^{5}$ Thus this study was carried out to assess the skills of caregivers of their child with Cerebral Palsy and to evaluate the impact of a Self Instructional Module that is an Information Booklet on Skills of caregiver who taking care of child with Cerebral Palsy.

\section{Research Methodology}

This study uses the quantitative research approach. A preexperimental study with one group pre-test post-test research design was considered best sited to the study. This design was used since the study evaluated the effect of selfinstructional module (independent variable) on skills of caregivers (dependent variables).

From different sampling techniques, the investigator adapted non-probability purposive sampling technique. Purposive or judgmental sampling is based on the belief that investigator's knowledge about population that can be used to handpick the cases to be included in the sample.

\section{Inclusion criteria}

- Caregiver who taking care of child with Cerebral Palsy between 1-14 years old.

- Caregiver who is willing to participate in the study.

- Caregiver who is available at the time of data collection.

- Caregiver who understand English, Marathi.

- Caregiver who is attending the Bharati Hospital of Pune city.

- Caregiver over 18 years of age of both genders. 


\section{International Journal of Science and Research (IJSR) \\ ISSN (Online): 2319-7064}

Index Copernicus Value (2013): 6.14 | Impact Factor (2013): 4.438
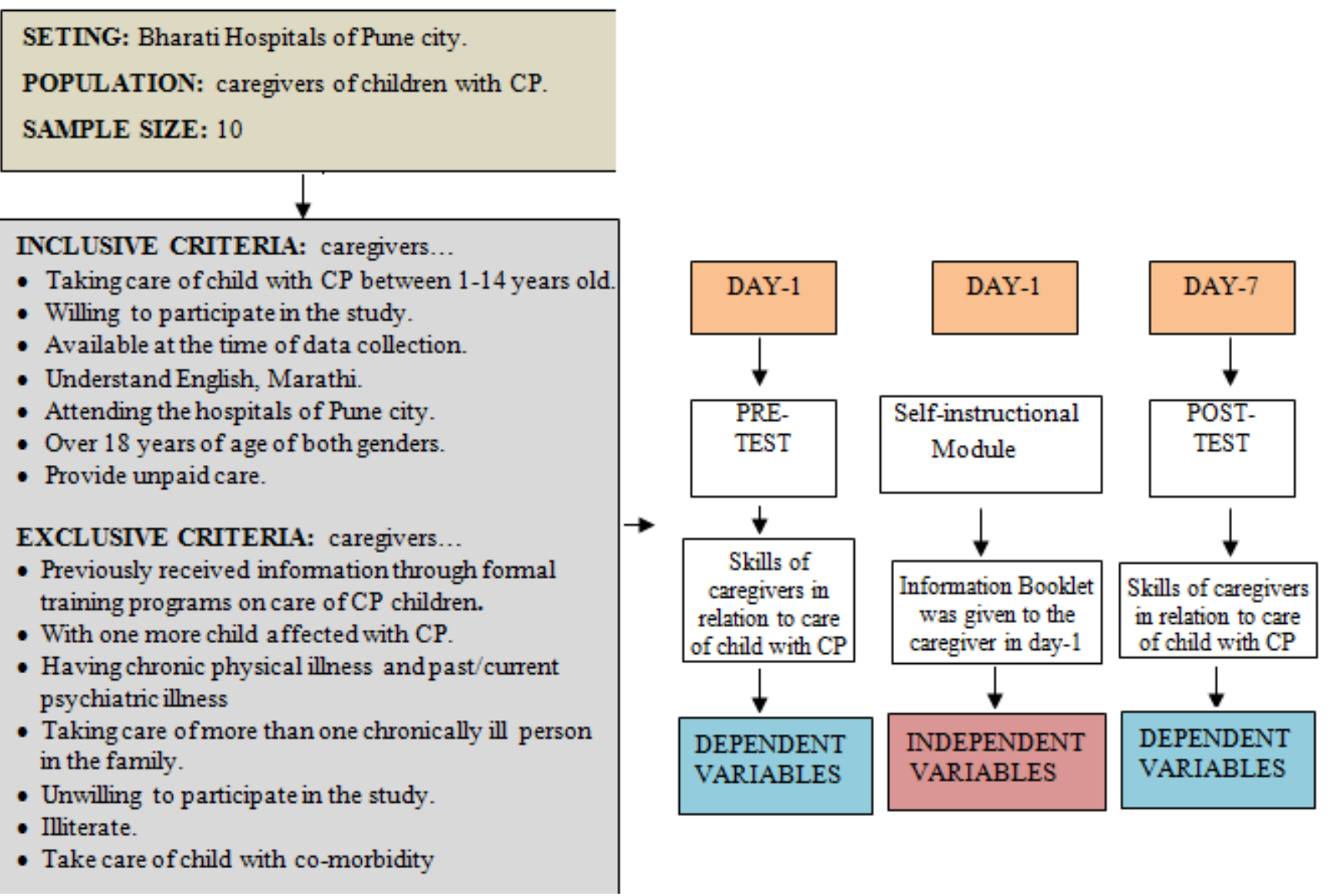

Figure 1: Schematic Representation of Research Design

\section{Description of the Tool}

\section{Section I: Demographic profile}

Section one was prepared to collect general information about the child with Cerebral Palsy and his/her caregiver. It is a case report sheet about variables such as:

\section{- Facts about child}

This consisted of the facts about child such as sex, date of birth, cause of Cerebral Palsy, associated condition, and other sibling affected.

\section{- Facts about caregiver}

This consist of the facts about caregiver such as sex, date of birth, type of relationship to child, marital status, education level, work status, monthly income, type of family, residence, how many days per week responsible for caregiving activities, family history of Cerebral Palsy, previous exposure of caring Cerebral Palsy, previous exposure of information regarding Cerebral Palsy, source of information and question regarding overall all health of child.

\section{Section II: Self reported practice questionnaire}

Self-reported practice questionnaire for assessment of skills of caregivers in relation to care of child with Cerebral Palsy at selected events.

The skills are groups into five dimensions:

Positioning \& Carrying, Communication, Feeding, Activity of daily living and Use of assistive devices. Scores for each dimension are expressed as a percentage of the maximum score for the dimension and the total score is obtained by averaging percentage scores the five dimensions (Russel et al., 2000).

For each skill in a domain, there are different items represents the assessment of practical of caregiver before and after intervention. The scoring based in a 6-point scale for each item using the following key.

For each skill in a domain, there are different items represents the assessment of practical of caregiver before and after intervention. The scoring based in a 6-point scale for each item using the following key.

0 - Impossible

1 - Very difficult

2 - Difficult

3 - Slightly difficult

4 -Easy

5 -Very easy

6 -No problem at all

This is further divided into:

A.For carrying and positioning domain, there are 9 items thus for each item the range of the scores varies between $0-54$. This range is further divided into the following categories for discussion purpose:

- Poor: 0-18

- Average: 17-36

- Good: 37-54

B. There are 10 items for Communication domain thus for each item the range of the scores varies between $0-60$. This 


\section{International Journal of Science and Research (IJSR) \\ ISSN (Online): 2319-7064 \\ Index Copernicus Value (2013): 6.14 | Impact Factor (2013): 4.438}

range is further into the following categories for discussion purpose:

- Poor: 0-20

- Average: 21-40

- Good: 41-60

C. There are 7 items for Feeding domain. Each item is further divided into the following categories for discussion purpose:

- Poor: 0-6

- Average: 7-13

- Good: 14-20

D. There are 8 items in Activity of daily living domain the range of score is divided into 0 to 48 . This is further divided into:

- Poor: 0-16

- Average: 17-32

- Good: 33-48

E. In Use of assistive devices domain there are 5 items and range of score is divided in to 0 to 30 . This is further divided into:

- Poor: 0-10

- Average: 11-20

- Good: 21-30

\section{Results and Analysis}

\section{Section I: Demographic profile}

Finding related to analysis of demographic data of samples.

\section{- Facts about child}

Majority of children with Cerebral Palsy were males while female children with Cerebral Palsy included a small population and none of these children had other siblings affected by Cerebral Palsy.

According to caregivers $30 \%$ of children had Cerebral Palsy after birth, $30 \%$ of them had it during birth, another $30 \%$ of them don't know the cause of Cerebral Palsy and only 10\% of them had Cerebral Palsy before birth.

\section{- Facts about caregiver}

All caregivers were female who taking care of child with Cerebral Palsy

Half $(50 \%)$ of caregivers had secondary education, $40 \%$ of them were graduates and $10 \%$ of them had primary education. All of them were homemakers. Half (50\%) of caregivers had monthly income more than Rups. 15000. Half $(50 \%)$ of them had joint family and another half $(50 \%)$ of them had nuclear family. Majority of $90 \%$ of caregivers were from urban area. $100 \%$ of caregivers engaged for care giving activities for 7 days in a week.

Section II: Finding related to analysis of the data related to the effectiveness of self-instructional module on skills among study subjects in relation to care of child with Cerebral Palsy.

This section presents the effectiveness of self-instructional module on skills of caregivers of children with Cerebral
Palsy. The data was analyzed using paired sample $t$ tests and significance was estimated at $(99 \%)$ confidence interval.

This section analyzed under underlying heading:

IIA) Comparison of overall skills during pre-test and posttest

IIB) Comparison of item wise gain in skills during pre-test and post-test in each aspect

II-A

This part deals with the overall analysis of subjects related to skills of caregivers of children with Cerebral Palsy in terms of frequencies, percentage, average, and t values.

In table 1 , In relation to overall skills of caregivers of children with Cerebral Palsy, most of participants $(60 \%)$ had scored average skills during pre-test while $(70 \%)$ of subjects had average skills during post-test.This shows that there is improvement in the skills of caregivers of children with Cerebral Palsy after self-instructional module.

Table 1: Distribution related to overall pre-test and post-test scores on skills of caregivers of children with Cerebral Palsy after administration of self-instructional module in terms of frequency and percentage, $\mathrm{N}=10$

\begin{tabular}{|c|c|c|c|c|}
\hline \multirow{2}{*}{ Skills } & \multicolumn{2}{|c|}{ Pre-test } & \multicolumn{2}{c|}{ Post-test } \\
\cline { 2 - 5 } & Freq & $\%$ & Freq & $\%$ \\
\hline Poor (Score $<34 \%$ ) & 4 & $40 \%$ & 3 & $30 \%$ \\
\hline Average (Score 34\%-66\%) & 6 & $60 \%$ & 7 & $70 \%$ \\
\hline Good (Score $>=67 \%$ ) & 0 & $0 \%$ & 0 & $0 \%$ \\
\hline
\end{tabular}

Skills of caregivers of children with cerebral palsy $\square$ Pretest $\square$ Posttest

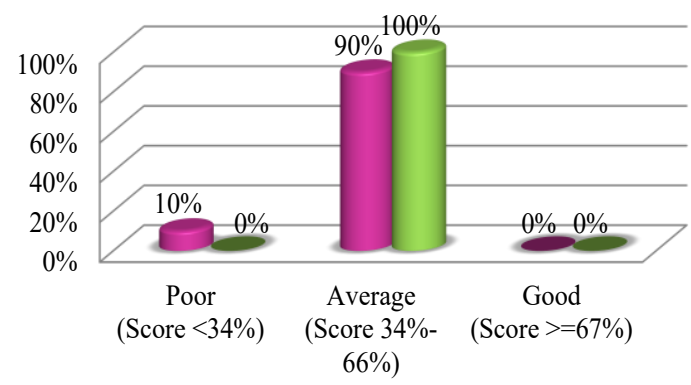

Figure 2: displays overall pre-test and post-test skills scores of caregivers of children with Cerebral Palsy

Table 2: Mean skills scores before and after the administration of self-instruction module among caregivers of children with Cerebral Palsy $\quad \mathrm{N}=10$

\begin{tabular}{|l|l|l|l|l|l|}
\hline Skills & Mean & $S D$ & $T$ & $d f$ & p-value \\
\cline { 1 - 3 } Pre-test & $52.8 \%$ & $21.3 \%$ & & & \\
\cline { 1 - 3 } Post-test & $68.0 \%$ & $8.8 \%$ & 3.1 & 9 & 0.007 \\
\hline
\end{tabular}

Investigator applied paired t-test for comparison of pre-test and post-test skill scores of caregivers of children with Cerebral Palsy. Average skill score in pre-test was 52.8\%, which was $68 \%$ in post-test. T-value for this comparison was 3.1 with 9 degrees of freedom. Corresponding p-value was 0.007 and considered to be statistically significant at $5 \%$ level of significant $(\mathrm{P}<0.005)$ thus self-instructional module improved the skills of caregivers of children with Cerebral Palsy significantly. 


\section{International Journal of Science and Research (IJSR) \\ ISSN (Online): 2319-7064}

Index Copernicus Value (2013): 6.14 | Impact Factor (2013): 4.438

Mean skill score of caregivers of children with cerebral palsy

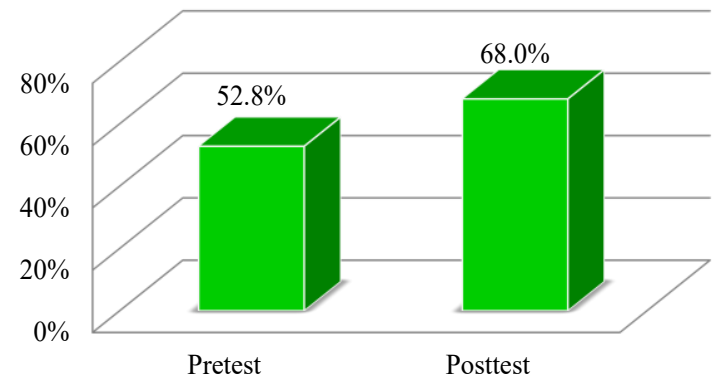

Figure 3: Overall Mean Skills of caregivers of children with Cerebral Palsy after administration of self-instructional module.

\section{II-B}

Findings related to analysis of data related to the skills of caregivers of children with Cerebral Palsy in each aspects that was categorized into skills related to carrying \& positioning, communication, feeding, activities of daily living, and use of assistive devices as follows:

\section{A.Finding related to carrying and positioning skill}

Table 3 shows that a majority $(50 \%)$ of the samples had average skills score with relation to carrying \& positioning their child with Cerebral Palsy in the pre-test while in the post-test a marginal development in skills was seen with $(60 \%)$ of samples having good scores.

Table 3: The effect of self-instructional module on Carrying $\&$ Positioning skills of caregivers of children with Cerebral Palsy

\begin{tabular}{|c|c|c|c|c|}
\hline Positioning \& Carrying & \multicolumn{2}{|c|}{ Pre-test } & \multicolumn{2}{c|}{ Post-test } \\
\cline { 2 - 5 } Skill & Freq & $\%$ & Freq & $\%$ \\
\hline Poor (Score 0-18) & 2 & $20.0 \%$ & 1 & $10.0 \%$ \\
\hline Average (Score 17-36) & 5 & $50.0 \%$ & 3 & $30.0 \%$ \\
\hline Good (Score 37-54) & 3 & $30.0 \%$ & 6 & $60.0 \%$ \\
\hline
\end{tabular}

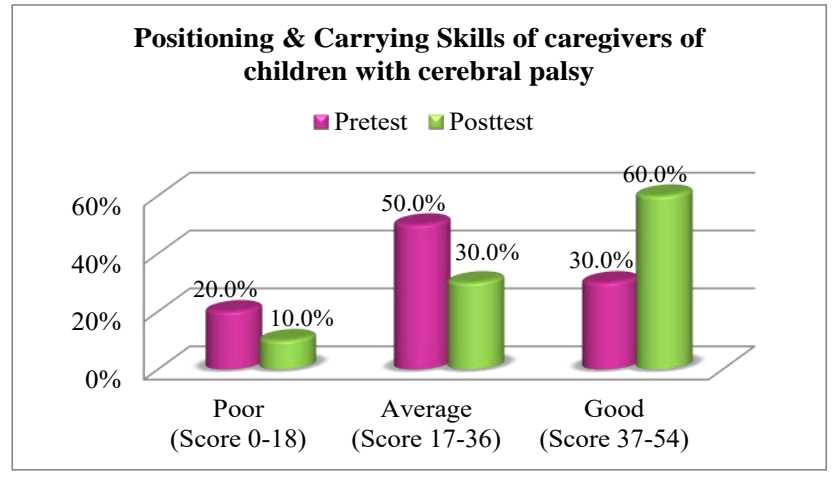

Figure 4: Distribution of subjects based on Carrying \& positioning skill

\section{B.Findings related to communication skill}

Table 4, data related to the percentage scores in each aspect is presented. It was seen that the scores among (71.4\%) of caregivers for communication from poor in pre-test and hasincreased to average among (57.1\%) of caregivers during post-test. The communication skills of caregivers improved remarkably after self-instructional module.
Table 4: The effect of self-instructional module on Communication skills of caregivers of children with Cerebral Palsy

\begin{tabular}{|l|l|c|l|c|}
\hline \multirow{2}{*}{ Communication Skill } & \multicolumn{2}{|c|}{ Pre-test } & \multicolumn{2}{c|}{ Post-test } \\
\cline { 2 - 5 } & Freq & $\%$ & Freq & $\%$ \\
\hline Poor (Score 0-20) & 5 & $71.4 \%$ & 3 & $42.9 \%$ \\
\hline Average (Score 21-40) & 3 & $42.9 \%$ & 4 & $57.1 \%$ \\
\hline Good (Score 41-60) & 2 & $28.6 \%$ & 3 & $42.9 \%$ \\
\hline
\end{tabular}

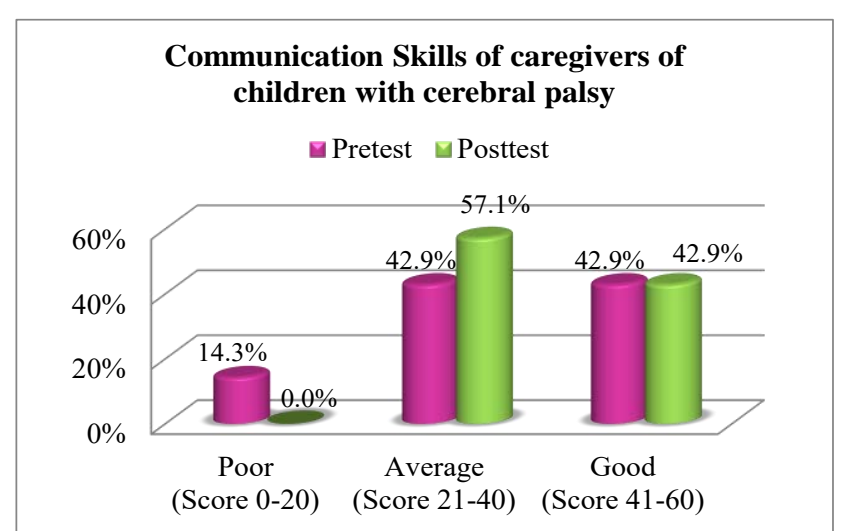

Figure 5: Distribution of subjects based onCommunication skill

\section{C.Finding related to the Feeding skill}

Tables 5 displays the analysis of item wise skills of caregivers. Out of 10 instances for feeding skills noticed most of samples $70 \%$ had poor skills during pre-test and only $30 \%$ of samples accounted as good during post-test. This indicates that the feeding skills of caregivers improved after self-instructional module.

Table 5: The effect of self-instructional module on Feeding skill of caregivers of children with Cerebral Palsy

\begin{tabular}{|l|l|l|l|l|}
\hline \multirow{2}{*}{ Feeding Skill } & \multicolumn{2}{|c|}{ Pre-test } & \multicolumn{2}{c|}{ Post-test } \\
\cline { 2 - 5 } & Freq & $\%$ & Freq & $\%$ \\
\hline Poor (Score 0-6) & 7 & $70.0 \%$ & 7 & $70.0 \%$ \\
\hline Average (Score 7-13) & 2 & $20.0 \%$ & 0 & $0.0 \%$ \\
\hline Good (Score 14-20) & 1 & $10.0 \%$ & 3 & $30.0 \%$ \\
\hline
\end{tabular}

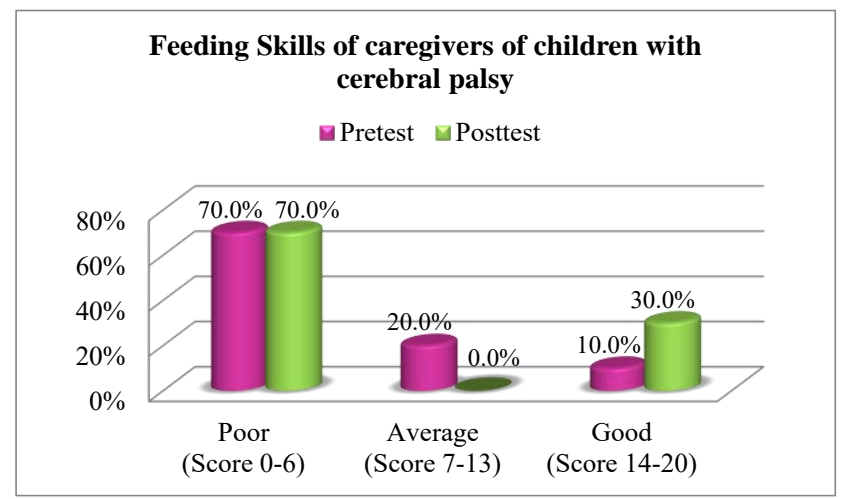

Figure 6: Distribution of subjects based on Feeding skill

D.Finding related to the Activity of daily living skills skill As seen in table 6, there was change in $40 \%$ subject's score from good during pre-test to $50 \%$ of subject's score during post-test.In pre-test, $40 \%$ of the caregivers had good skills (score 33-48) and in post-test, 50\% of them had good skills (score 33-48) had scored on activity of daily living. This indicates that the activity of daily living skills of caregivers improved after self-instructional module. 


\section{International Journal of Science and Research (IJSR) \\ ISSN (Online): 2319-7064 \\ Index Copernicus Value (2013): 6.14 | Impact Factor (2013): 4.438}

Table 6: The effect of self-instructional module on Activity of Daily Living skill of caregivers of children with Cerebral Palsy

\begin{tabular}{|c|c|c|c|c|}
\hline \multirow{2}{*}{ Activity of Daily Living skill } & \multicolumn{2}{|c|}{ Pre-test } & \multicolumn{2}{c|}{ Post-test } \\
\cline { 2 - 5 } & Freq & $\%$ & Freq & $\%$ \\
\hline Poor (Score 0-16) & 3 & $30.0 \%$ & 3 & $30.0 \%$ \\
\hline Average (Score 17-32) & 3 & $30.0 \%$ & 2 & $20.0 \%$ \\
\hline Good (Score 33-48) & 4 & $40.0 \%$ & 5 & $50.0 \%$ \\
\hline
\end{tabular}

Activity of daily living Skills of caregivers of children with cerebral palsy

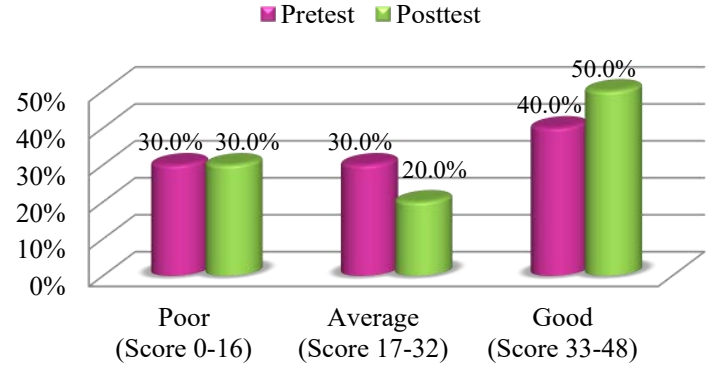

Figure 7: Distribution of subjects based on Activity of Daily Living skill

\section{E. Finding related to the use of assistive devices}

Table 7 also shows that $70 \%$ caregivers scored poor in use assistive devices during pre-test and 50\% caregivers accounted to use assistive devices during post-test, which indicates that the use of assistive device improved after selfinstructional module

Table 7: The effect of self-instructional module on Use of Assistive Device skill of caregivers of children with Cerebral

\begin{tabular}{|c|c|c|c|c|}
\hline \multirow{2}{*}{ Use of Assistive Device skill } & \multicolumn{2}{|c|}{ Pre-test } & \multicolumn{2}{c|}{ Post-test } \\
\cline { 2 - 5 } & Freq & $\%$ & Freq & $\%$ \\
\hline Poor (Score 0-10) & 7 & $70.0 \%$ & 4 & $40.0 \%$ \\
\hline Average (Score 11-20) & 2 & $20.0 \%$ & 5 & $50.0 \%$ \\
\hline Good (Score 21-30) & 1 & $10.0 \%$ & 1 & $10.0 \%$ \\
\hline
\end{tabular}

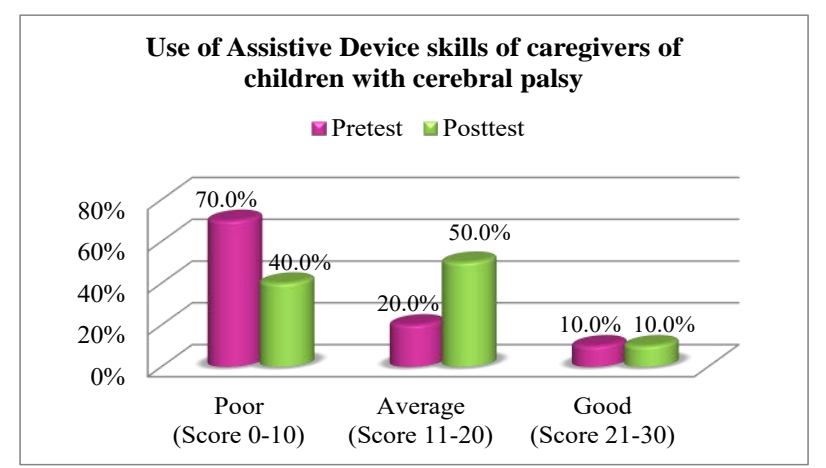

Figure 8: Distribution of subjects based on Use of Assistive Device skill

\section{Discussion}

The study concluded that there was a significant increase in the skills of caregivers of children with Cerebral Palsy as evidenced by an increase in the mean skills scores in the post-test $(52.8 \%$ in the pre-test to $68 \%$ in the post-test). Skills of caregivers before and after administration of Information Booklet were assessed in five aspects carrying and positioning, communication, feeding, activities of daily living, and use of assistive devices. Distributions of subjects during post-test were higher as compared during pre-test in each aspect.It is supported by the Pre-experimental study (one group pre-test post-test) performed in Karnataka (India) to assess the effect of self-instructional module in knowledge and skills regarding use of Glasgow Coma Scale neurological assessment of patients among nurses working in critical care units. Self-instructional module was administered after pre-test and 7 days later post-test was conducted. The result marked that there was significant gain in knowledge and skill among staff nurses working in critical care units after administration of Self-Instructional Module. (Teles, Bhupali\&Madhale, 2013) ${ }^{6}$

The results of this study cannot be generalized to all children with Cerebral Palsy, as the size of sample in this study was small. It was very difficult to isolate the self-instructional module from those of other sources like mass media, friends, Internet, magazine etc.

\section{Conclusion}

The study concluded that there was a significant increase in the mean skills of caregivers of children with Cerebral Palsy scores from $52 \%$ in the pre-test to $68 \%$ in the post-test. Skills of caregivers before and after administration of Information Booklet and assessed in 5 aspects carrying \& positioning, communication, feeding, activities of daily living, and use of assistive devices.

\section{Scope o the Study}

In India caregivers are members of family who regularly take care of and support an ill person within that family. This includes everything from managing diets, administrating medicines, scheduling doctor's visits, coordinating home health care, to ensuring the physical and emotional need of the ill person or family member are being met. This is often a full time job, not one that someone applies for or is paid to do, but one that arises and must be filled within a family.

\section{Acknowledgement}

The Author is thankful to administrative authority of Bharati Vidyapeeth college of Nursing and Bharati Hospital for their cooperation.

\section{References}

[1] Jones Martha Wilson, Morgan Elaine, Shelton Jean E. primary care of the child with cerebral palsy: A review of systems (part II). J Pediatr Health Care. 2007 Jul; 21(4): 226-237. Doi: 10.1016/j.pedhc.2006.07.003

[2] Zolotor Adam J. Kane Mollie. Chapter 49: Disorder of Behavior and Development. In: Sloane Philip D., Slatt Lisa M., Ebell Mark H., Smith Mindy A., Power David, Viera Anthony J. editors. Essentials of Family Medicine. $6^{\text {th }}$ ed. Philadelphia, PA: Lippincott Williams \& Wilkins, Wolters Kluwer; 2012. P. 575-586. ISBN: 9781608316557. 


\section{International Journal of Science and Research (IJSR) \\ ISSN (Online): 2319-7064}

Index Copernicus Value (2013): 6.14 | Impact Factor (2013): 4.438

[3] Cunningham Robert D. Delay in referral to earlyintervention services. Pediatrics. 2004 Apr; 114(3): 896. Doi: 10.1542/peds.2004-0941

[4] Harbourne Regina T. Willett Sandra L. Kyvelidou Anastasia, Deffeyes Joan, Stergiou Nicholas. A comparison of intervention for children with cerebral palsy to improve sitting postural control: A Clinical Trial. Journal Articles. 2010 Dec; 90(12): 1881-1898. Doi: 10.2522/ptj.2010132.

[5] KhannaAroraShilpa, AggarwalAniu, Mittal Hema. Impact of an Educational Film on Parental Knowledge of Children with Cerebral Palsy. Int J Pediatr. 2014 March; 2014(573698): 1-4.

Doi: http://dx.doi.org/10.1155/2014/573698

[6] Teles Marian, BhupaliPreeti, MadhaleMilka. Effectiveness of Self Instructional Module on Knowledge and Skills Regarding Use of Glasgow Coma Scale in Neurological Assessment of Patients among Nurses Working in Critical Care Units of KLE Dr. PrabhakarKore Hospital and Medical Research Centre, Belgaum. Journal of Krishna Institute of Medical Sciences University. 2013 Jan-Jun; 2(1): 98-104.

[7] Alok Sharma. Parent guide for cerebral palsy. MatungaLabour Camp Mumbai: NeuroGen Brain \& Spine Institute. , India: Surekha Press; 2014.

\section{Author Profile}

Ms. ImanBadran, received the M.Sc. Nursing from Bharati Vidyapeeth, Pune, India in 2009 and presently registered as Ph.D. Nursing in Bharati Vidyapeeth , Pune India in 2012. 